\title{
Mathematical models for foam-diverted acidizing and their applications
}

\author{
Li Songyan ${ }^{1}$, Li Zhaomin ${ }^{1 *}$ and Lin Riyi ${ }^{2}$ \\ ${ }^{1}$ School of Petroleum Engineering, China University of Petroleum, Dongying, Shandong 257061, China \\ ${ }^{2}$ School of Transport \& Storage and Civil Engineering, China University of Petroleum, Dongying, Shandong 257061, China
}

\begin{abstract}
Foam diversion can effectively solve the problem of uneven distribution of acid in layers of different permeabilities during matrix acidizing. Based on gas trapping theory and the mass conservation equation, mathematical models were developed for foam-diverted acidizing, which can be achieved by a foam slug followed by acid injection or by continuous injection of foamed acid. The design method for foam-diverted acidizing was also given. The mathematical models were solved by a computer program. Computed results show that the total formation skin factor, wellhead pressure and bottomhole pressure increase with foam injection, but decrease with acid injection. Volume flow rate in a highpermeability layer decreases, while that in a low-permeability layer increases, thus diverting acid to the low-permeability layer from the high-permeability layer. Under the same formation conditions, for foamed acid treatment the operation was longer, and wellhead and bottomhole pressures are higher. Field application shows that foam slug can effectively block high permeability layers, and improve intake profile noticeably.
\end{abstract}

Key words: Foam slug, foamed acid, diversion, acidizing, nonhomogenous, mathematical model

\section{Introduction}

Matrix acidizing process The main purpose of matrix acidizing treatment is to improve the formation permeability, especially the damaged sandstone or carbonate formations caused by drilling, completion, or production processes, to enable enhanced production of reservoir fluids. A damaged formation has plugged or constricted pore spaces, reduced permeability and productivity. In acidizing treatment, acid is used to dissolve the materials plugged in matrix pore spaces, thus increasing the formation porosity, permeability and productivity.

Several layers having different porosities, permeabilities and rock types were developed in the damaged formation, and these layers may differ in the degree of damage after a period of production. In matrix acidization, all damaged layers need to be treated, especially the most severely damaged layers. However, fluid naturally flows into the most-permeable, leastdamaged layers, and may leave less-permeable and moredamaged layers untreated. To solve this problem, foam is used to partially block the high-permeability and undamaged layers, diverting acid into the low-permeability layers (Cheng et al, 2001; Kennedy et al, 1992; Smith et al, 1969; Zerhboub et al, 1994).

Foam for acid diversion Many researchers (Bernard et al, 1965; de Vries and Wit, 1990; Friedmann and Jensen, 1986; Friedmann et al, 1991; Huh et al, 1989; Sanchez and

*Corresponding author. email: Lizhm@hdpu.edu.cn

Received October 22, 2007
Schechter, 1989) agreed that foam does not increase water or acid viscosity, or alter the relationship between water relative permeability and water saturation in steady foam flow. Foam directly reduces gas mobility in rocks, the low-mobility gas in turn drives down water saturation, thereby reducing water relative permeability and mobility. Foam reduces gas mobility in part by trapping a high percentage of gas in place; up to $80-99 \%$ of gas is trapped even if foam flows at a high pressure gradient (Bretherton 1961; Falls et al, 1988; Hirasaki and Lawson, 1985; Hirasaki, 1989; Rossen, 1990). On the other hand, the presence of foam can increase the effective viscosity of flowing gas, thus reducing gas mobility (Hill and Rossen, 1994; Gdanski et al, 1993; Radke and Gillis, 1990; Rossen, 1996). Both effects are related to each other. The apparent yield stress of foam increases at high capillary pressure, and many bubbles in foam are trapped in place. The presence of foam in a high-permeability or undamaged layer can reduce liquid saturation and relative liquid permeability, thereby reducing acid flow into the foam-saturated layers.

Foams are less stable in low-permeability or damaged layers (Gdanski, 1993; Hill and Rossen, 1994). Acid can then be diverted into these layers without zonal isolation. The use of a surfactant pre-flush can improve acid diversion by helping to place more foams in high-permeability or undamaged layers (Radke and Gillis, 1990). Therefore it is possible to block high-permeability zones preferentially during acid injection.

The key to a successful acid diversion in matrix acidization is to place as much gas as possible into undamaged or high-permeability layers during foam injection, 
and then trap as much of this gas as possible in place during subsequent acid injection, to reduce liquid mobility and thus facilitate diversion from those layers. Foam is not effective unless it keeps gas trapped during subsequent injection of liquid (acid) (Hill and Rossen, 1994; Radke and Gillis, 1990; Sanchez and Schechter, 1989). Moreover, accurate prediction of foam effectiveness requires predicting the extent of gas trapping during post-foam liquid injection, and the relative permeability to liquid during this period.

Foam diversion techniques in matrix acidization Two foam diversion techniques are adopted to divert acid from higher-permeability layers to lower-permeability ones in matrix acidization: 1) Surfactant preflush followed by alternating slugs of foam and foam-compatible acid. The foam-compatible acid must contain surfactants to stabilize the foam. It is so-called acid diversion by using foam slugs in matrix acidization. 2) Surfactant preflush followed by continuous injection of foamed acid. It is so-called foamedacid diversion in matrix acidization. This study focused on both processes. Mathematical models for foam flow were established, and diversion processes were simulated. A field application was presented and discussed.

\section{Mathematical models for acid diversion by using foam slugs in matrix acidizing}

In matrix acidizing, diversion is a critical step to ensure acid flow into the desired layers. As the analysis mentioned above, foam can decrease the permeability difference of layers. If gas can be trapped in the formations, diversion and acidization could be effective. Based on gas trapping theory and the mass conservation equation, mathematical models for acid diversion by using foam slugs were established. Because foam injection and subsequent acid injection are two different processes, mathematical models were researched respectively.

\subsection{Mathematical model for foam flow}

The radius of penetration of foam can be expressed as follows:

$$
R_{\mathrm{fi} i}(t)=\sqrt{\frac{\int_{0}^{t} q_{\mathrm{fi}}(t) \cdot \Gamma(t) \mathrm{d} t}{\pi H_{i} \varphi_{i}\left(1-S_{\mathrm{wc}}\right)}+R_{\mathrm{w}}^{2}}
$$

Pseudo skin factor due to gas trapping

$$
S_{\mathrm{p} i}(t)=\left(\frac{K_{i}}{K_{\mathrm{f} i}}-1\right) \ln \frac{R_{\mathrm{fi}}(t)}{R_{\mathrm{w}}}
$$

Flow rate of foam in each layer is

$$
q_{\mathrm{fi}}(t)=\frac{2 \pi H_{i} \cdot K_{i} \cdot\left[p_{\mathrm{w}}(t)-p_{\mathrm{e}}\right]}{\mu_{\mathrm{f}}\left[\ln \frac{R_{\mathrm{e}}}{R_{\mathrm{w}}}+S_{i}+S_{\mathrm{p} i}(t)\right]}
$$

The total injected volumetric flow rate of foam is

$$
\sum_{i=1}^{n} q_{\mathrm{fi}}(t)=q_{1}+q_{\mathrm{g}}(t)
$$

The volumetric flow rate of gas is

$$
q_{\mathrm{g}}(t)=\frac{T_{\mathrm{e}}}{p_{\mathrm{w}}(t)} \frac{z \cdot q_{\mathrm{gsc}} p_{\mathrm{gsc}}}{T_{\mathrm{gsc}}}
$$

Foam quality (volume fraction gas in foam) is

$$
\Gamma(t)=\frac{q_{\mathrm{g}}(t)}{q_{1}+q_{\mathrm{g}}(t)}
$$

Relative injection rate into each layer is

$$
f_{i}(t)=\frac{q_{\mathrm{fi}}(t)}{q_{1}+q_{\mathrm{g}}(t)}
$$

Initial conditions:

The initial bottomhole pressure is reservoir pressure, and the foam quality at bottomhole is set as $0.6-0.8$.

$$
\begin{aligned}
& t=0, \quad p_{\mathrm{w}}=p_{\mathrm{e}} \\
& t=0, \quad \Gamma=0.7
\end{aligned}
$$

Constraint conditions:

The volumetric flow rate of liquid in foam is constant, the volumetric flow rate of gas in foam is also constant under standard conditions, and the bottomhole pressure is less than the formation fracture pressure.

$$
\begin{gathered}
q_{1}=\text { const } \\
q_{\mathrm{gsc}}=\text { const } \\
p_{\mathrm{w}}(t)<p_{\text {frac }} \\
p_{\text {frac }}=p_{\mathrm{e}}+\left(\frac{\mathrm{v}}{1-\mathrm{v}}\right) \sigma
\end{gathered}
$$

where $i$ is layer number; $n$ is the number of total layers; $R_{\mathrm{f}}$ is the radius of penetration of foam during foam injection, $\mathrm{m} ; q_{\mathrm{f} i}$ is the volumetric flow rate of foam in layer $i, \mathrm{~m}^{3} / \mathrm{s} ; t$ is foam injection time, $\mathrm{s} ; \quad \Gamma$ is foam quality, fraction; $H$ is layer thickness, $\mathrm{m} ; \varphi$ is formation porosity, fraction; $S_{\mathrm{wc}}$ is immobile water saturation, fraction; $R_{\mathrm{w}}$ is the radius of well bore, m; $S_{\mathrm{p}}$ is pseudo skin factor due to gas trapping; $K$ is initial formation permeability, D; $K_{\mathrm{f}}$ is formation permeability after foam injection, $\mathrm{D} ; p_{\mathrm{w}}$ is bottomhole pressure, $\mathrm{MPa} ; p_{\mathrm{e}}$ is formation pressure, MPa; $\mu_{\mathrm{f}}$ is foam viscosity, Pa.s; $R_{\mathrm{e}}$ is the diameter of oil drainage, $\mathrm{m} ; S$ is the initial skin factor of the formation; $q_{1}$ is the volumetric flow rate of liquid in foam, $\mathrm{m}^{3} / \mathrm{s} ; q_{\mathrm{g}}$ is the volumetric flow rate of gas in foam, $\mathrm{m}^{3} / \mathrm{s} ; T_{\mathrm{e}}$ is formation temperature, $\mathrm{K} ; z$ is compressibility factor for gas; $q_{\mathrm{gsc}}$ is the volumetric flow rate of gas in foam under standard conditions, $\mathrm{m}^{3} / \mathrm{s} ; f$ is relative injection rate into each layer, fraction; $p_{\mathrm{gsc}}$ is standard pressure, $0.1 \mathrm{MPa} ; T_{\mathrm{gsc}}$ is standard temperature, $273 \mathrm{~K} ; p_{\text {frac }}$ is formation fracture pressure, $\mathrm{MPa}$; $v$ is Poisson's ratio of formation rock; $\sigma$ is the formation stress in the vertical direction, MPa. 


\subsection{Mathematical model for acid flow}

The radius of penetration of foam during acid injection can be expressed as follows:

$$
R_{\mathrm{f} i}(t)=\sqrt{\frac{\pi\left(R_{\mathrm{F} i}^{2}-R_{\mathrm{w}}^{2}\right) H_{i} \varphi_{i}+\int_{0}^{t} q_{\mathrm{a} i}(t) \mathrm{d} t}{\pi H_{i} \varphi_{i}\left[1-S_{\mathrm{w} i}(t)\right]}+R_{\mathrm{w}}^{2}}
$$

Water saturation is

$$
S_{\mathrm{w} i}(t)=1-\frac{\pi\left(R_{\mathrm{fi}}^{2}-R_{\mathrm{w}}^{2}\right) H_{i} \varphi_{i} \Gamma(t)}{\pi\left(R_{\mathrm{F} i}^{2}-R_{\mathrm{w}}^{2}\right) H_{i} \varphi_{i}+\int_{0}^{t} q_{\mathrm{ai}} t}
$$

The water relative permeability for layer $i$ during subsequent acid injection can expressed as follows:

$$
K_{\mathrm{a} i}(t)=K_{i} K_{\mathrm{r}}\left(S_{\mathrm{w} i}\right)
$$

Pseudo skin factor due to gas trapping

$$
S_{\mathrm{p} i}(t)=\left[\frac{K_{i}}{K_{\mathrm{a} i}(t)}-1\right] \ln \frac{R_{\mathrm{fi}}(t)}{R_{\mathrm{w}}}
$$

Flow rate of acid in layer $i$ can be expressed as follows:

$$
q_{\mathrm{a} i}(t)=\frac{2 \pi H_{i} \cdot K_{i} \cdot\left[p_{\mathrm{w}}(t)-p_{\mathrm{e}}\right]}{\mu_{\mathrm{a}}\left[\ln \frac{R_{\mathrm{e}}}{R_{\mathrm{w}}}+S_{i}+S_{\mathrm{p} i}(t)+S_{\mathrm{a} i}(t)\right]}
$$

The total injected volumetric flow rate of acid is

$$
\sum q_{\mathrm{a} i}(t)=q_{\mathrm{a}}
$$

Relative injection rate into each layer is

$$
f_{i}(t)=\frac{q_{\mathrm{ai}}(t)}{q_{\mathrm{a}}}
$$

Skin factor due to an acidizing treatment is

$$
\begin{gathered}
S_{\mathrm{a} i}(t)=-c \cdot \int_{0}^{t} q_{\mathrm{a} i} t \quad \int_{0}^{t} q_{\mathrm{a} i} t<Q_{\mathrm{n}} \\
S_{\mathrm{a} i}(t)=-S_{i} \quad \int_{0}^{t} q_{\mathrm{a} i} t \geq Q_{\mathrm{n}}
\end{gathered}
$$

Initial conditions:

The initial bottomhole pressure is the pressure at the end of foam slug injection.

$$
t=0, \quad p_{\mathrm{w}}=p_{\mathrm{f}}
$$

Constraint conditions: Acid volume flow rate is constant, and the bottomhole pressure is less than formation fracture pressure.

$$
\begin{gathered}
q_{\mathrm{a}}=\text { const } \\
p_{\mathrm{w}}<p_{\text {frac }} \\
p_{\text {frac }}=p_{\mathrm{e}}+\left(\frac{\mathrm{v}}{1-\mathrm{v}}\right) \sigma
\end{gathered}
$$

where $R_{\mathrm{F}}$ is foam radius at the end of foam injection, $\mathrm{m} ; S_{\mathrm{w}}$ is water saturation during acid injection, fraction; $q_{\mathrm{a}}$ is acid injection flow rate, $\mathrm{m}^{3} / \mathrm{s} ; \mu_{\mathrm{a}}$ is acid viscosity, $\mathrm{Pa} \cdot \mathrm{s} ; S_{\mathrm{a}}$ is skin factor due to acid; $Q_{\mathrm{n}}$ is the total volume of acid required to remove formation damage, $\mathrm{m}^{3}$.

\subsection{Solution to the mathematical models}

The pseudo skin factor due to gas trapping is related to the volume of foam injected into different layers, and the foam volume injected is affected by the pseudo skin factor due to gas trapping. The fractional flow in different layers thereby could not be obtained by an analytic method, but only with a numerical method. After the relationship between bottomhole pressure and time has been established, the relationship of wellhead pressure and flow rate with time can be obtained by calculating the flow in wellbore. Finally, operation parameters for foam acidizing can be determined.

\subsection{Principles for acid diversion by using foam slugs in matrix acidizing}

In order to obtain excellent efficiency of diversion, some principles are presented according to laboratory investigation and field application.

1) Foam quality must be between 0.6 to 0.8 at bottomhole pressure and temperature (Gdanski, 1993; Alvarez el al, 2000).

2) The volume of each foam slug injected is 1.5 to 2 times as large as the open-hole volume in reservoir bed under bottomhole conditions (Morphy el al, 1998).

3) Surfactants must be added into both preflush and subsequent acid to stabilize the foam fluid (Zhou and Rossen, 1994).

4) The number of foam slugs should be less than 4 to avoid complication during field application (Morphy el al, 1998).

\section{Mathematical model for foamed-acid diversion}

For a continuous injection of foamed acid into the formation, the model for this process is similar to that for foam flow in matrix acidizing. There is an additional skin factor due to acid during foamed acid injection, Eq. (3) can be modified in the following form.

$$
q_{\mathrm{fi}}(t)=\frac{2 \pi H_{i} \cdot K_{i} \cdot\left[p_{\mathrm{w}}(t)-p_{\mathrm{e}}\right]}{\mu_{\mathrm{f}}\left[\ln \frac{R_{\mathrm{e} i}}{R_{\mathrm{w}}}+S_{i}+S_{\mathrm{p}}(t)+S_{\mathrm{a} i}(t)\right]}
$$

The solution procedures of mathematical model for foamed acid flow are similar to foam flow discussed above in the acid diversion by using foam slugs.

\section{Matrix acidizing treatment design}

\subsection{Acid diversion by using foam slugs}

An oil well, selected for foam slug diverted acidizing, has 
the following well parameters and operation parameters, as shown in Table 1. Formation parameters for each layer are shown in Table 2. Five layers having different permeabilities were developed in this reservoir bed. The relationships of skin factor, bottomhole pressure, and wellhead pressure with time during acidizing were calculated with the mathematical models developed above and presented in Fig.1 through Fig. 3. Design results and pumping schedule of treating fluids are shown in Table 3 through Table 5.

Calculated results of acid diversion by using foam slugs indicate that foam has the ability to block formation. During foam injection, the total skin factor (including pseudo skin factor due to gas trapping, which can be eliminated in the sequential acidizing operation) increases, but the initial

Table 1 Basic well parameters

\begin{tabular}{cc}
\hline Parameter & Value \\
\hline Wellbore diameter, $\mathrm{m}$ & 0.278 \\
Inner diameter of tubing, $\mathrm{m}$ & 0.078 \\
Formation pressure, $\mathrm{MPa}$ & 20.0 \\
Formation temperature, ${ }^{\circ} \mathrm{C}$ & 75 \\
Temperature gradient, ${ }^{\circ} \mathrm{C} / 100 \mathrm{~m}$ & 3.0 \\
$\quad$ Vertical formation depth, $\mathrm{m}$ & 2000 \\
Formation fracture pressure, $\mathrm{MPa}$ & 30.0 \\
Foam quality at bottomhole & 0.7 \\
Volumetric flow rate of nitrogen, $\mathrm{Nm}{ }^{3} / \mathrm{h}$ & 600 \\
Volumetric flow rate of acid, $\mathrm{m}^{3} / \mathrm{h}$ & 30 \\
Volumetric flow rate of preflush, $\mathrm{m}^{3} / \mathrm{h}$ & 30 \\
\hline
\end{tabular}

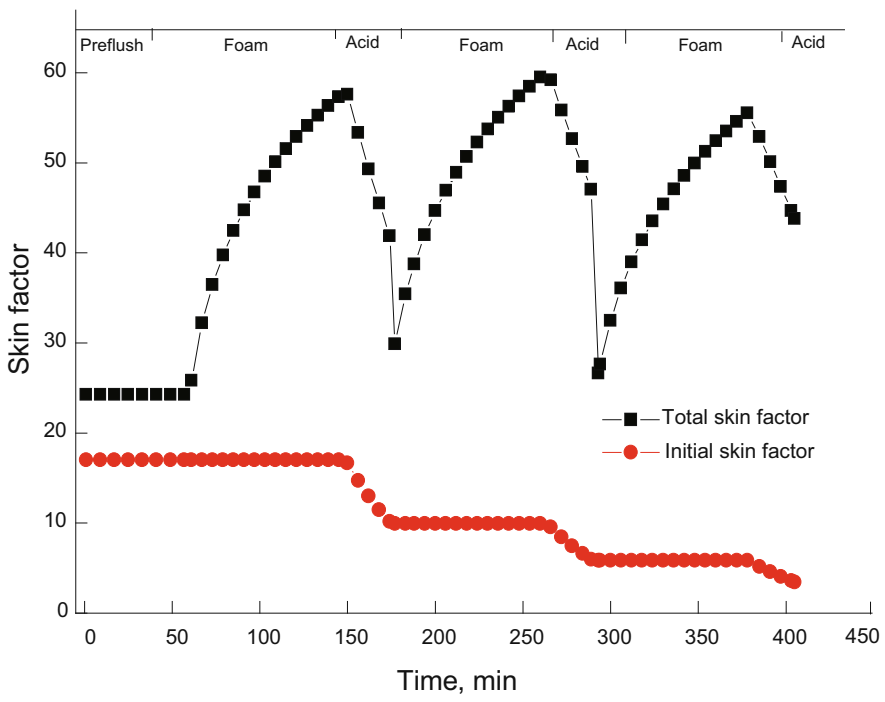

Fig. 1 Evolution of skin factor in a matrix acidizing treatment by using foam slugs for diversion

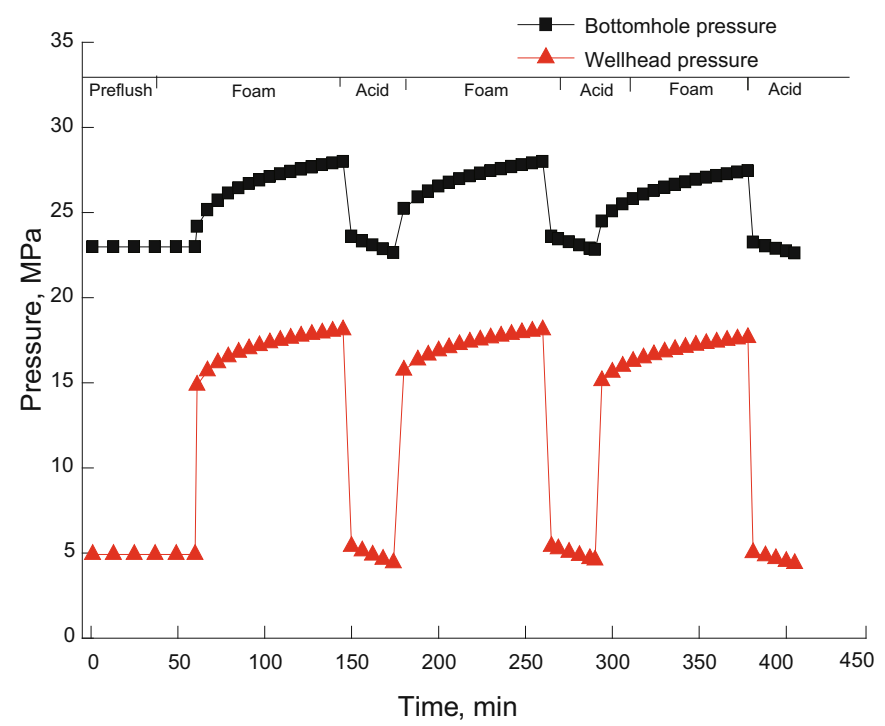

Fig. 2 Evolution of wellhead and bottomhole pressures in a matrix acidizing treatment by using foam slugs for diversion

Table 2 Basic parameters of layers

\begin{tabular}{ccccccc}
\hline Layer No. & $\begin{array}{c}\text { Permeability } \\
\mathrm{mD}\end{array}$ & Porosity & $\begin{array}{c}\text { Diameter of oil } \\
\text { drainage } \\
\mathrm{m}\end{array}$ & $\begin{array}{c}\text { Thickness } \\
\mathrm{m}\end{array}$ & $\begin{array}{c}\text { Immobile water } \\
\text { saturation }\end{array}$ & Skin factor \\
\hline 1 & 900 & 0.26 & 200 & 10 & 0.29 & 20 \\
2 & 600 & 0.26 & 200 & 10 & 0.29 & 18 \\
3 & 400 & 0.26 & 200 & 10 & 0.29 & 15 \\
4 & 200 & 0.26 & 200 & 10 & 0.29 & 15 \\
\hline
\end{tabular}


Table 3 Design results of foam slug diverted acidizing

\begin{tabular}{ccccc}
\hline $\begin{array}{c}\text { Nitrogen volume } \\
\text { Nm3 }\end{array}$ & $\begin{array}{c}\text { Acid volume } \\
\mathrm{m} 3\end{array}$ & Foam slug & $\begin{array}{c}\text { The highest wellhead pressure } \\
\text { MPa }\end{array}$ & $\begin{array}{c}\text { Total operation time } \\
\mathrm{h}\end{array}$ \\
\hline 2682 & 40.1 & 3 & 18.2 & 5.8 \\
\hline
\end{tabular}

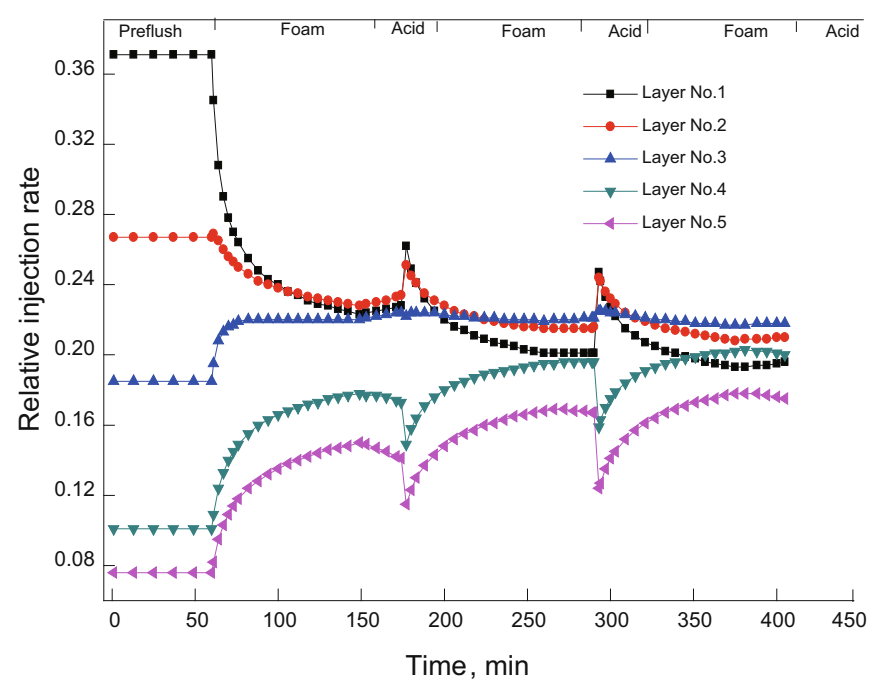

Fig. 3 Relative injection rate into each layer in a matrix acidizing treatment by using foam slugs for diversion

Table 4 Pumping schedule of treating fluids

\begin{tabular}{cc}
\hline Slug & Treating fluids \\
\hline Preflush & Liquid $30 \mathrm{~m}^{3}$ \\
\hline First & $\mathrm{N}_{2} 894 \mathrm{Nm}^{3}+$ liquid $1.82 \mathrm{~m}^{3}$ \\
& Acid $13.4 \mathrm{~m}^{3}$ \\
\hline Second & $\mathrm{N}_{2} 894 \mathrm{Sm}^{3}+$ liquid $1.82 \mathrm{~m}^{3}$ \\
& ${\text { Acid } 13.4 \mathrm{~m}^{3}}^{3}$ \\
\hline Third & $\mathrm{N}_{2} 894 \mathrm{Sm}^{3}+$ liquid $1.82 \mathrm{~m}^{3}$ \\
& Acid $13.4 \mathrm{~m}^{3}$ \\
\hline
\end{tabular}

Table 5 Diversion results of acid

\begin{tabular}{cc}
\hline Layer No. & $\begin{array}{c}\text { Volume of acid injected into each layer } \\
\mathrm{m}^{3}\end{array}$ \\
\hline 1 & 8.07 \\
2 & 8.52 \\
3 & 8.59 \\
4 & 7.46 \\
5 & 6.37 \\
\hline
\end{tabular}

skin factor due to formation damage remains constant; and bottomhole pressure and wellhead pressure increase. During subsequent acid injection, the total skin factor and initial skin factor due to formation damage decrease because of flushing of foam in place by acid and dissolution of formation damage by acid. Wellhead pressure decreases gradually. Bottomhole and wellhead pressures during acid injection are much lower than those values during foam injection.

During foam injection, the increment rate of the pseudo skin factor of low-permeability layers is higher than that of high-permeability layers. Foam flow rate through a high-permeability layer decreases, and that through a lowpermeability layer increases. During acid injection, the ability of foam to block the formation reduces because of flushing of foam in place by acid. The flow rate of acid in a highpermeability layer increases, but that in a low-permeability layer decrease. The highest bottomhole and wellhead pressures appear at the end of foam slug injection. The rated pump pressure on the ground must be higher than the highest wellhead pressure in field practice.

\subsection{Foamed-acid diversion}

In order to compare treatment performance of the two kinds of foam-diverted acidizing, a design for the same oil well was drawn up for matrix acidizing by using foamed acid was made. The relationships of skin factor, bottomhole pressure, and wellhead pressure with time during acidizing were calculated with the mathematical model developed above. The results are shown in Figs. 4, 5, and 6. Design results and pumping schedule of treating fluids are shown in Tables 6 and 7.

For a continuous injection of foamed acid into five layers having different permeabilities and initial skin factors, foam has the ability to block formation. The total skin factor increases, but the initial skin factor due to formation damage decreases during acidizing. Bottomhole and wellhead

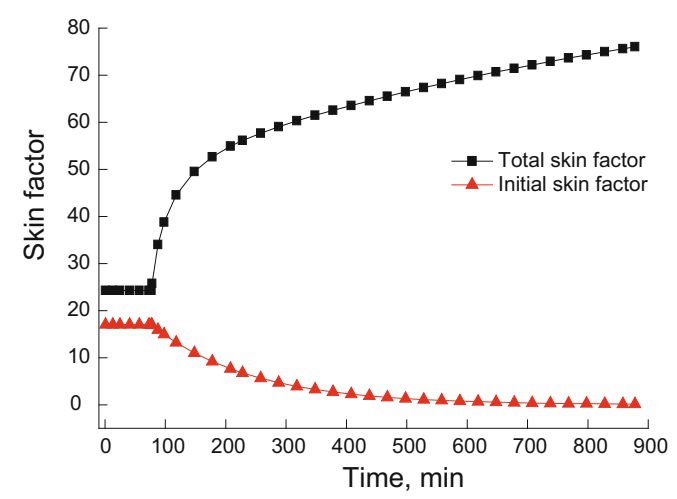

Fig. 4 Evolution of skin factor in a foamed-acid treatment 
Table 6 Design results of a foamed-acid treatment

\begin{tabular}{cccc}
\hline $\begin{array}{c}\text { Nitrogen volume } \\
\mathrm{Nm}^{3}\end{array}$ & $\begin{array}{c}\text { Acid volume } \\
\mathrm{m}^{3}\end{array}$ & $\begin{array}{c}\text { Highest wellhead pressure } \\
\mathrm{MPa}\end{array}$ & $\begin{array}{c}\text { Total operation time } \\
\mathrm{h}\end{array}$ \\
\hline 7482 & 40.1 & 22.4 & 13.4 \\
\hline
\end{tabular}

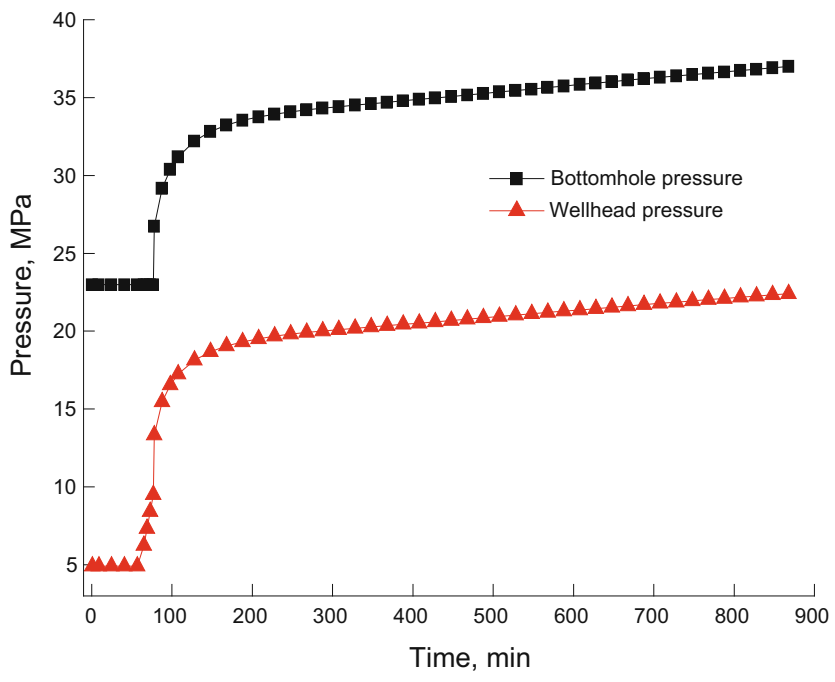

Fig. 5 Evolution of wellhead and bottomhole pressures in a foamed-acid treatment

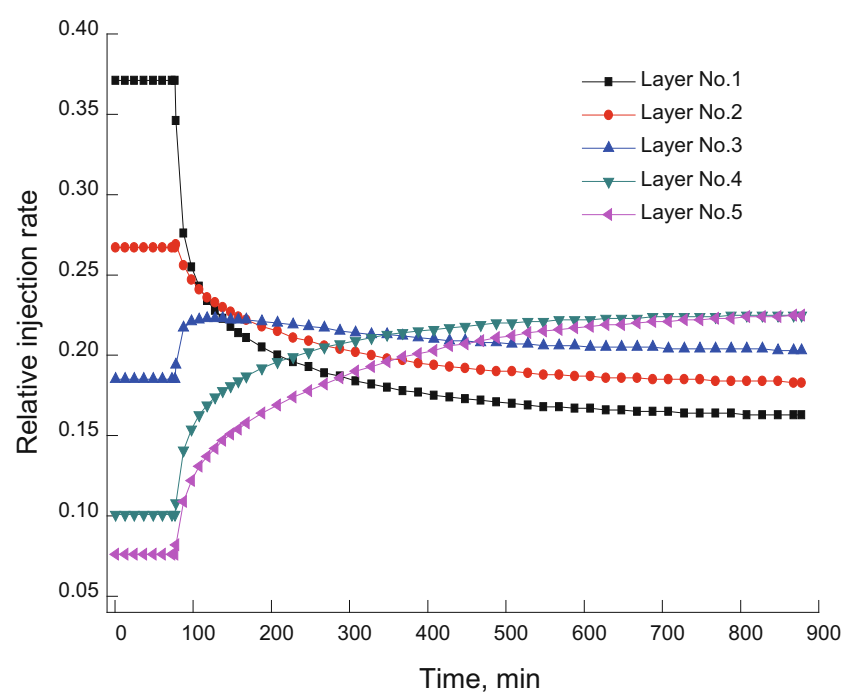

Fig. 6 Relative injection rate in each layer a foamed-acid treatment

Table 7 Diversion results of acid in a foamed-acid treatment

\begin{tabular}{cc}
\hline Layer No. & $\begin{array}{c}\text { Volume of acid injected into each layer } \\
\mathrm{m}^{3}\end{array}$ \\
\hline 1 & 7.29 \\
2 & 7.95 \\
3 & 8.44 \\
4 & 8.46 \\
5 & 7.96 \\
\hline
\end{tabular}

pressures increase. At the beginning of foamed acid injection (less than an hour), pressure increases sharply, and then it increases slowly. Flow rates of foamed acid in highpermeability layers decrease, but those in low-permeability layers increase with increasing volume of foamed acid injected, therefore the foamed acid flows into each layer. The highest bottomhole and wellhead pressures appear at the end of foamed acid injection.

Compared with conventional acidizing, foam is very effective in diverting acid into desired layers (Fig. 7). Under the same formation conditions, diversion efficiency of foamed acid is higher than that of the foam slug alternative. The acid injected into different layers is more uniform during matrix acidizing by using foamed acid. However, continuous nitrogen injection is required, and the flow rate of acid is reduced. The total operation time of matrix acidizing job is much longer. Because the total skin factor and bottomhole pressure increase with injection time during foamed acid injection, it is easy for the bottomhole pressure to exceed formation fracture pressure.

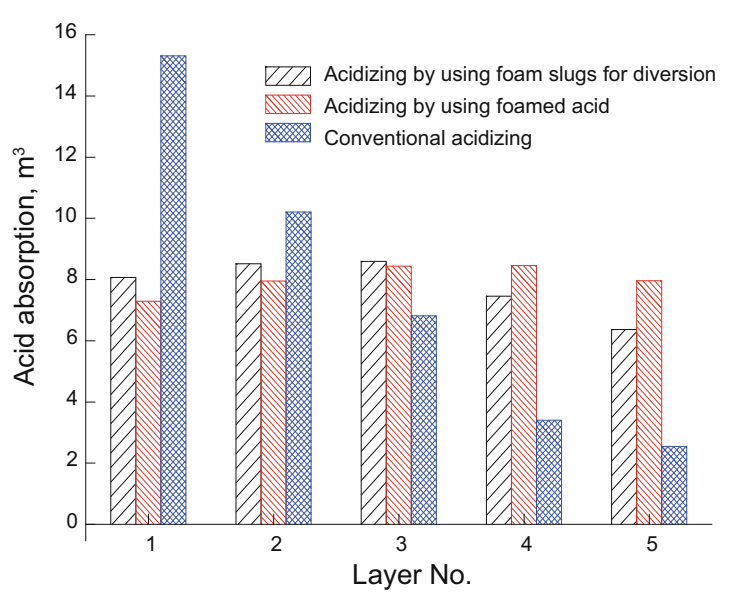

Fig. 7 Results of different diversion methods

\section{Field application of foam slug diverted acidizing}

Foam acidizing can be used in three kinds of formations: For thick oil formations having different permeability layers, foam can preferentially block high-permeability layers, diverting acid into low-permeability layers. For the formations needed to be re-treated, foam can preferentially block corroded channels formed in the previous acid treatment. For the formations having oil-water layers, foam can preferentially block the water zone, avoiding high water cut after acidizing.

The foam slug followed by acid injection was used in 
Well S32, a downflow well, in DZ32-4 Oilfield in 2007. There were 6 layers with different permeabilities. Injection pressure was very high because of formation damage near the wellbore. Production logging shows that the intake profile was extremely non-uniform. Conventional acidizing treatment could not solve this problem, so the use of foam slug for diversion of acid from high-permeability layers to low-permeability layers could be effective. The basic well parameters are shown in Table 8.

Table 8 Basic parameters for Well S32

\begin{tabular}{cc}
\hline Parameter & Value \\
\hline Well type & Directional well \\
Production mode & Downflow well \\
Inclined depth, $\mathrm{m}$ & 1834.00 \\
Vertical depth, $\mathrm{m}$ & 1572.45 \\
Formation pressure, MPa & 12.57 \\
Formation temperature, ${ }^{\circ} \mathrm{C}$ & 60.56 \\
Porosity, $\%$ & $25-35$ \\
Permeability, $\mathrm{mD}$ & $18.0-13582.9$ \\
Commissioning date & 2001.04 \\
\hline
\end{tabular}

During acidizing, responses of wellhead pressure and flow rate with time are shown in Fig. 8. During the foam slug injection (two foam slugs) wellhead pressure increased, which accorded with the predicted results from the models developed above. Production logging (Table 9) after acidizing shows that intake profiles were significantly improved, and two more layers were utilized.

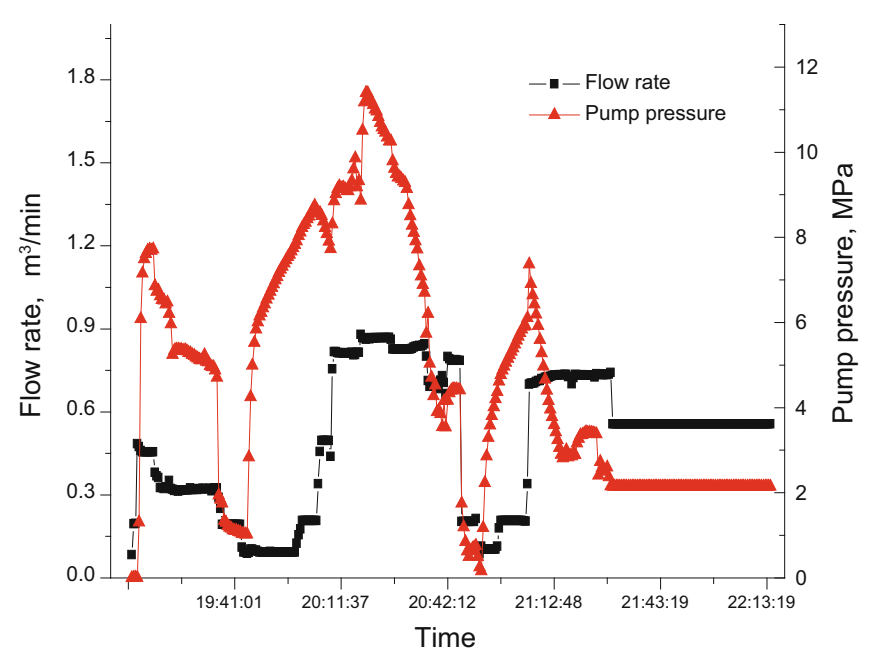

Fig. 8 Pump pressure and flow rate during injection

Table 9 Injection profile tests before and after acidizing

\begin{tabular}{|c|c|c|c|c|c|c|c|}
\hline \multirow[b]{2}{*}{ Layer No. } & \multirow[b]{2}{*}{$\begin{array}{l}\text { Perforated interval } \\
\mathrm{m}\end{array}$} & \multirow[b]{2}{*}{$\begin{array}{c}\text { Thickness } \\
\mathrm{m}\end{array}$} & \multirow[b]{2}{*}{$\begin{array}{l}\text { Permeability } \\
\mathrm{mD}\end{array}$} & \multicolumn{2}{|c|}{ Before acidizing } & \multicolumn{2}{|c|}{ After acidizing } \\
\hline & & & & $\begin{array}{c}\text { Water absorption } \\
\mathrm{m}^{3} / \mathrm{d}\end{array}$ & $\begin{array}{c}\text { Relative water } \\
\text { absorption } \\
\%\end{array}$ & $\begin{array}{l}\text { Water absorption } \\
\mathrm{m}^{3} / \mathrm{d}\end{array}$ & $\begin{array}{c}\text { Relative water } \\
\text { absorption } \\
\%\end{array}$ \\
\hline 1 & $1506.5-1509.6$ & 2.5 & 2452.3 & 0 & 0 & 42.8 & 6.4 \\
\hline 2 & $1542.0-1552.4$ & 8.1 & 4124.3 & 244.8 & 43.3 & 175.05 & 26 \\
\hline 3 & $1568.4-1579.8$ & 9.1 & 13582.9 & 307.9 & 54.4 & 154.2 & 22.9 \\
\hline 4 & $1583.4-1594.9$ & 9.2 & 11696.4 & 13.2 & 2.3 & 145.47 & 21.6 \\
\hline 5 & $1603.9-1604.6$ & 2.6 & 798.6 & 0 & 0 & 155.57 & 23.1 \\
\hline 6 & $1610.4-1611.3$ & 0.7 & 18.0 & 0 & 0 & 0 & 0 \\
\hline
\end{tabular}

\section{Conclusions}

1) Mathematical models for acid diversion by using foam slugs and foamed acid respectively were established and solved by a computer program, which can be used to design foam-diverted acidizing.

2) For foam slug treatment followed by acid slug injection, during foam slug injection, the total skin factor, bottomhole pressure and wellhead pressure increase, however, during the subsequent acid slug injection, the initial skin factor due to formation damage decreases. Foam can divert acid from highpermeability layers into low-permeability layers.

3) Under the same formation conditions, diversion efficiency of foamed acid is higher than that of foam slug. The acid injected into different layers is more uniform during matrix acidizing by using foamed acid. Because the skin factor increases during foamed acid injection, bottomhole pressure is easy to exceed formation fracture pressure.

4) A field application of foam-slug diverted acidizing shows that the intake profile was improved significantly, and 
two more layers were utilized after acidizing. Foam diverted acidizing was effective for nonhomogenous formations.

\section{References}

Alvarez J M, Rivas H, Navarro G, el al. An optional foam quality for diversion in matrix-acidizing projects. SPE International Symposium on Formation Damage Control held in Lafayette, Louisiana, 23-24 February, 2000 (SPE paper 58711)

Bernard G G, Holm L W and Jacobs W L. Effect of foam on trapped gas saturation and on permeability of porous media to water. SPE Journal. 1965. 5(4): 295-300 (SPE paper 1204)

Bretherton F P. The motion of long bubbles in tubes. Journal of Fluid Mechanics. 1961. 10: 166-188

Cheng L, Kam S I, Delshad M, el al. Simulation of dynamic foam-acid diversion processes. SPE European Formation Damage Conference held in The Hague, Netherlands, 21-22 May, 2001 (SPE paper 68916)

de Vries A S and Wit K. Rheology of gas/water foam in the quality range relevant to steam foam. SPE Reservoir Engineering. 1990. 5(2): 185-192 (SPE paper 18075)

Falls A H, Hirasaki G J, Patzek T W, el al. Development of a mechanistic foam simulator: The population balance and generation by snap-off. SPE Reservoir Engineering. 1988. 3(3): 884-892 (SPE paper 14961)

Friedmann F, Chen W H and Gauglitz P A. Experimental and simulation study of high-temperature foam displacement in porous media. SPE Reservoir Engineering. 1991. 6(1): 37-45 (SPE paper 17357)

Friedmann F and Jensen J A. Some parameters influencing the formation and propagation of foams in porous media. SPE California Regional Meeting held in Oakland, California, 2-4 April, 1986 (SPE paper 15087)

Gdanski R D. Experience and research show best designs for foamdiverted acidizing. Oil \& Gas Journal. 1993. 85-89

Hill A D and Rossen W R. Fluid placement and diversion in matrix acidizing. University of Tulsa Centennial Petroleum Engineering Symposium held in Tulsa, Oklahoma, 29-31 August, 1994 (SPE paper 27982)
Hirasaki G J. The steam foam process. Journal of Petroleum Technology. 1989. 41(5): 449-456 (SPE paper 19505)

Hirasaki G J and Lawson J B. Mechanisms of foam flow in porous media: Apparent viscosity in smooth capillaries. SPE Journal. 1985. 25(2): 176-190 (SPE paper 12129)

Huh D G and Handy L L. Comparison of steady- and unsteady-state flow of gas and foaming solution in porous media. SPE Reservoir Engineering. 1989. 4(1): 77-84 (SPE paper 15078)

Kennedy D K, Kitziger F W and Hall B E. Case study on the effectiveness of nitrogen foams and water-zone diverting agents in multistage matrix acid treatment. SPE Production Engineering. 1992. 7(2): 203-211 (SPE paper 20621)

Morphy P H, Greenwald K G and Herries P E. Operational experience with foam-diverted acid jobs in the Gulf of Mexico. Journal of Petroleum Technology. 1998. 50(3): 44-45 (SPE paper 39423)

Radke C J and Gillis J V. A dual-gas tracer technique for determining trapped gas saturation during steady foam flow in porous media. SPE Annual Technical Conference and Exhibition held in New Orleans, Louisiana, 23-26 September, 1990 (SPE paper 20519)

Rossen W R. Theory of mobilization pressure gradient of flowing foams in porous media I: Incompressible foam. Journal of Colloid and Interface Science. 1990. 136(1): 1- 53

Rossen W R. Foams in enhanced oil recovery. In books: Foams: Fundamentals and applications. - Ed. by Prud'homme R K and Khan S. New York: Marcel Dekker. 1996. 413-464

Sanchez J. M. and Schechter R. S. Surfactant effects on the two-phase flow of steam-water and nitrogen-water through permeable media. Journal of Petroleum Science \& Engineering.1989. 3(1-2): 185-199

Smith C L, Anderson J L and Roberts P G. New diverting techniques for acidizing and fraction. SPE California Regional Meeting held in San Francisco, California, 6-7 November, 1969 (SPE paper 2751)

Zerhboub M, Ben-Naceur K, Touboul E, el al. Matrix acidizing: A novel approach to foam diversion. SPE Production \& Facilities. 1994. 9(2): 121-126 (SPE paper 22854)

Zhou Z H and Rossen W R. Applying fractional-flow theory to foams for diversion in matrix acidization. SPE Production \& Facilities. 1994. 9(1): 29-35 (SPE paper 24660)

(Edited by Sun Yanhua) 